\title{
MEASURING CASH FLOW AND OVERDRAFT FOR FUZZY PROJECT NETWORKS WITH OVERLAPPING ACTIVITIES
}

\author{
Min-Chun YUa, Van-Loi DANG ${ }^{\mathrm{b}}$, Hui-Chung $\mathrm{YEH}^{\mathrm{a}}$ \\ ${ }^{a}$ Department of Business Administration, National Kaohsiung University of Applied Sciences, \\ 415 Chien-Kung Road, Kaohsiung 807, Taiwan \\ ${ }^{b}$ Department of Industrial Engineering and Management, National Kaohsiung University of Applied Sciences, \\ 415 Chien-Kung Road, Kaohsiung 807, Taiwan
}

Received 17 Aug 2015; accepted 01 Feb 2016

\begin{abstract}
Overlapping activities with imprecise durations to accelerate schedules has an impact on scheduling a construction project. The project may need to be rescheduled to suit the available overdraft limitation rather than to adopt the least total cost schedule. However, past research has seldom conducted a risk analysis on the project cash flow and overdraft requirements for projects with overlapping activities in a fuzzy environment. This research uses fuzzy DSMbased scheduling and proposes an algorithm to calculate the cash flow and overdraft at different risk levels. A numerical example is illustrated to demonstrate the algorithm's effectiveness.
\end{abstract}

Keywords: project management, cash flow analysis, project overdraft, fuzzy sets.

\section{Introduction}

The modern construction industry relies on reductions in project completion time either to meet customer demands or when the project schedule runs late. There are five common techniques to compress schedules: working overtime, crashing, reducing scope, outsourcing, and doing series work in parallel (Kerzner 2013). However, crashing and fast tracking (overlapping) are widely used to shorten the project schedule without changing the project quality or scope (Snyder 2013).

When developing a project schedule, a single value, usually the most likely duration, is used to calculate the time for an activity. In fact, a project with uncertain activity durations is usually composed of a large number of interrelated tasks. The complexity of information dependencies between activities makes project scheduling difficult and uncertain (Chen et al. 2003). The main challenge is to reduce project duration while evaluating the degree of uncertainty. Schedule compression involves uncertainties, which may arise from variability and ambiguity (Khodakarami et al. 2007). Schedule compression either increases risks or requires additional resources, so risk must be taken into account (Shankar et al. 2011).

Mathematical and statistical models have been applied to cash flow forecasting (Kaka, Price 1991; Skitmore 1992). Easa (1992) introduced a mixed-integer optimization model that maximizes the contractor's profit for progress payment contracts, and formulated other scheduling objectives such as leveling and minimizing the maximum overdraft. Jeang (2015) developed a compromised multi-objective model by utilizing response surfacing methodology (RSM) to find the optimal schedule.

Project activities are sometimes required to overlap to a greater extent so that the construction projects can be completed in a short time span. Dubois and Gadde (2002) regarded the construction project as a loosely coupled system wherein an overlap of construction elements could happen due to the complexity and uncertainty in the industry.

When activities are overlapped to compress the project duration, the dependency structure matrix (DSM) is a powerful tool to plan the activity sequence (Maheswari, Varghese 2005). A DSM is a square matrix equipped with identical row and column labels that can display the relationships between the components of a system. Steward (1981) was the first to name the method "design structure matrix" for its application to the design process issues. The method was later expanded to general applications and conferred with the term "dependency structure matrix" (Browning 1998). According to a survey conducted by Browning (2001), there are two types of DSMs, namely static DSM and time-based DSM. The time-based DSM had been used to manage projects by implementing

Corresponding author: Min-Chun $\mathrm{Yu}$

E-mail:yminchun@cc.kuas.edu.tw 
its network precedence diagrams. The survey also noted that the use of DSM increased significantly in academic and industrial practice in the 1990s, especially for the construction, automotive, semiconductor, and telecommunication industries.

Shi and Blomquist (2012) show that it is not possible to accurately estimate overlapping activities in the planning stage of a project, and the solution calls for a robust methodology to manage schedules within uncertain conditions of information dependency. This research therefore proposes an approach using fuzzy set theory to solve the problem within an uncertain environment.

Hendrickson and Au (1989) find that borrowing options for contractors to bridge their expenditures and receipts during construction are relatively limited. For small or medium sized projects, overdrafts from bank accounts are the most common form of construction financing, though the bank usually imposes a maximum limit based on the expected expenditures and receipts for the duration of construction. When a construction is in progress, cash flow forecasting provides contractors with the amount of capital and interest that needs to be paid. Poor forecasting capability often leads to various financial risks (Hwee, Tiong 2002). Kazaz et al. (2012) point out that financial related risk factors such as delay of payments, cash flow problems and contractor's financial problems are primary causes of delays for construction projects. Cui et al. (2010) indicates that overdraft along with retainage, financing, payment and billing policies constitute the most significant financial issues for contractors when conducting cash flow management.

Halpin (2010) lists a number of factors affecting the overdraft amount, such as the amount of markup or profit the contractor has in their bid, the retainage amount, and the delay between billing and payment. Halpin and Senior (2011) point out that the peak financial requirements (the maximum overdraft) is an important factor that the contractor must be aware of in order to have enough money available to cover this maximum. These previous studies include overdraft amounts into their calculations. The maximum overdraft is especially important for a construction firm, as they will need to have bank credit available. It is therefore imperative to have techniques available to minimize the overdraft amount and their associated interest payments.

However, the current literature lacks estimations for overdrafts in projects that have activities with overlapping and fuzzy duration. Research on overlapping activities in construction emphasizes the importance of incorporating uncertainty factors in project overdraft forecasts, though there is little attention to identifying and quantifying the specific risks. This study focuses on assessing the effect of overlapping on project overdraft.

This study investigates the effect of overlapping project teams on a contractor's cash flow and overdraft requirements. The information exchanges used for overlapping are an important factor causing uncertainty in cash flows and overdraft requirements on a construction project, though contractors tend to reduce this type of uncertainty. To assist with this effort, this study proposes an algorithm to evaluate uncertainty in cash flows and overdraft requirements for projects that have overlapping activities with fuzzy duration.

The rest of the paper is organized as follows. Section 1 develops and proposes an algorithm to calculate project overdraft. Section 2 provides a numerical example to demonstrate the applicability of the proposed algorithm. Conclusions are presented at the end of paper.

\section{Proposed algorithm to measure project overdraft}

This study adopts the fuzzy project cash flow (Maravas, Pantouvakis 2012) and fuzzy DSM methods (Shi, Blomquist 2012) to develop a new algorithm to calculate project overdrafts based on a fuzzy approach to project scheduling. There are three steps to implement the algorithm.

Step 1: Manage schedule using the Dependency Structure Matrix

The DSM approach is useful for representing complex dependency relationships caused by information exchange between activities. This step takes into consideration the overlap between activities. Figure 1 shows activities $P$ (predecessor activity) and $S$ (successor activity). $P_{1}$ is the time required to release the information from activity $P$,
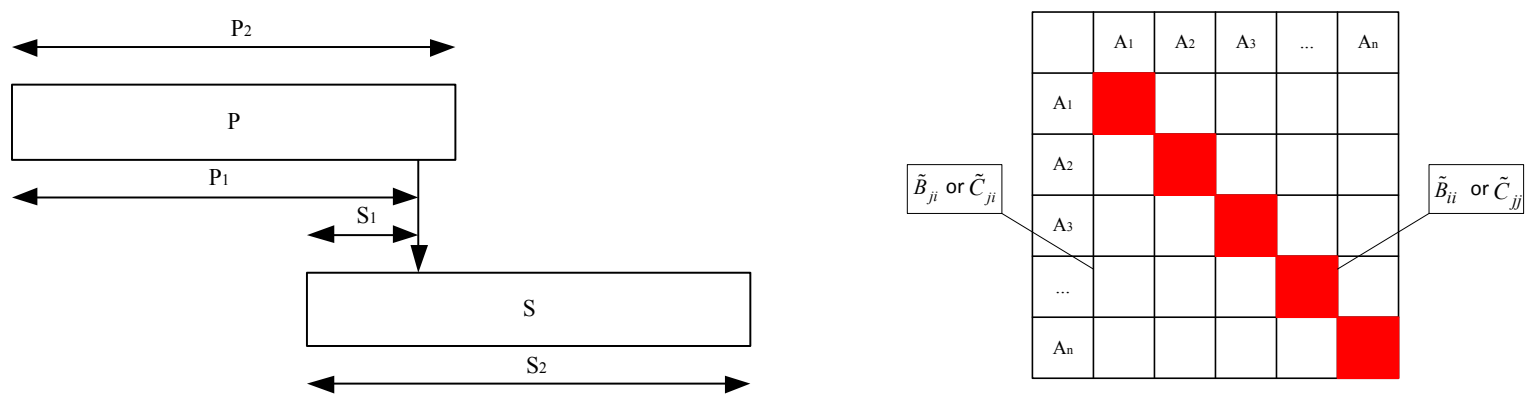

Fig. 1. Information transfer for the predecessor and the successor activities 
Table 1. Description of linguistic variables $\tilde{B}_{j i}$ and $\tilde{C}_{j i}$ using triangular fuzzy numbers

\begin{tabular}{cll}
\hline Fuzzy number & \multicolumn{1}{c}{$\tilde{B}_{j i}$} & \multicolumn{1}{c}{$\tilde{C}_{j i}$} \\
\hline $\mathrm{Q}_{1}(0.1,0.1,0.2)$ & $\begin{array}{l}\text { Required information can be released after a } \\
\text { small percentage of work has been finished. }\end{array}$ & $\begin{array}{l}\text { A small amount of work can take place before the } \\
\text { information is released from its predecessor activity. }\end{array}$ \\
\cline { 2 - 3 } $\mathrm{Q}_{2}(0.2,0.3,0.4)$ & $\begin{array}{l}\text { Required information can be released after } \\
\text { a percentage of work has been finished. }\end{array}$ & $\begin{array}{l}\text { Some work can take place before the information is } \\
\text { released from its predecessor activity. }\end{array}$ \\
\cline { 2 - 3 } $\mathrm{Q}_{3}(0.4,0.5,0.6)$ & Middle status & Middle status \\
\cline { 2 - 3 } $\mathrm{Q}_{4}(0.6,0.7,0.8)$ & $\begin{array}{l}\text { Required information can be released after } \\
\text { a large amount of work has been finished. }\end{array}$ & $\begin{array}{l}\text { A large amount of work can take place before the } \\
\text { information is released from its predecessor activity. }\end{array}$ \\
\cline { 2 - 3 } $\mathrm{Q}_{5}(0.8,0.9,0.9)$ & $\begin{array}{l}\text { Required information can be released after } \\
\text { almost all of the work has been finished. }\end{array}$ & $\begin{array}{l}\text { Almost all the work can be completed before the } \\
\text { information is released from its predecessor activity. }\end{array}$ \\
\hline
\end{tabular}

Source: Shi and Blomquist (2012).

and $P_{2}$ is the duration of $P$. The time factor for sending information from activity $P$ is calculated as $P_{1} / P_{2}$. Similarly, the time factor for receiving information related to activity $S$ will be $S_{1} / S_{2}$. The two matrices $B_{i j}$ (for all predecessor activities) and $C_{i j}$ (for all the successor activities) represent the time factor of information exchange and the duration of each activity and their relationships:

$$
\tilde{B}_{j i}=\frac{P_{1}}{P_{2}}, \tilde{C}_{j i}=\frac{S_{1}}{S_{2}},
$$

where $i$ is all the immediate predecessors of $j, j$ is the current activity in the order as identifies by partitioned DSM.

The earliest start/finish time of each activity is calculated using DSM:

$$
\begin{gathered}
(\widetilde{E S})_{j}=\max \left[(\widetilde{E S})_{i} \oplus\left(\tilde{B}_{j i} \otimes \tilde{B}_{i i}\right) \ominus\left(\tilde{C}_{j i} \otimes \tilde{C}_{j j}\right)\right] ; \\
0<i \leq n, 0<j \leq n ; \\
(\widetilde{E F})_{j}=\left(\widetilde{E S)_{j}} \oplus \tilde{C}_{j j} \quad 0<j \leq n,\right.
\end{gathered}
$$

where $n$ is the number of activities.

The latest start/finish time of each activity is calculated using DSM:

$$
\begin{gathered}
(\widetilde{L S})_{i}=\min \left[(\widetilde{L S})_{j} \oplus\left(\tilde{C}_{j i} \otimes \tilde{C}_{j j}\right) \oplus\left(\tilde{B}_{j i} \otimes \tilde{B}_{i i}\right)\right] \\
0<i \leq n, 0<j \leq n \\
(L F)_{j}=\left(\widetilde{L S)_{j}} \oplus B_{i i} \quad 0<j \leq n\right.
\end{gathered}
$$

where the earliest start of the first activity $\widetilde{E S}_{\text {start }}=(0,0,0)$ and the latest finish time of the last activity $\widetilde{L F}$ end $=D_{c p}$ (where $D_{c p}$ is the duration of the critical path). Here, $\tilde{B}_{j j}$ is equal to $\tilde{C}_{j j}$, which indicates that the duration of activity is same for both matrices.

To calculate the value of the time factors $\tilde{B}_{j i}$ and $\tilde{C}_{j i}$ for each activity, they must be transformed from a linguistic variable to a triangular fuzzy number. Fig- ure 2 illustrates the transformation rules. Table 1 lists the semantic rules for assigning one of five triangular fuzzy numbers to each of the basic linguistic terms.

Most existing studies are rather simple or did not mention that fuzzy numbers may represent the decision makers' subjective knowledge, an important aspect to consider. To overcome this problem, Shureshjani and Darehmiraki (2013) proposed a method to explicitly represent information about the decision maker's preferences.

The fuzzy maximum operator $\widetilde{\max }$ is based on the method of ranking the fuzzy number using $\alpha$ cut :

$$
\begin{aligned}
& Q_{\alpha}\left(\tilde{A}_{\omega}\right)=\int_{\alpha}^{\omega}\{\underline{A}(r)+\bar{A}(r)\} d r= \\
& 2 b(\omega-\alpha)+\frac{c-2 b+a}{2 \omega}(\omega-\alpha)^{2},
\end{aligned}
$$

where $\underline{A}(r)=a+\frac{b-a}{\omega} r, \bar{A}(r)=c-\frac{c-b}{\omega} r$.

When $\omega=1$, we have:

$$
Q_{\alpha}\left(\tilde{A}_{1}\right)=2 b(1-\alpha)+\frac{c-2 b+a}{2}(1-\alpha)^{2} \text {. }
$$

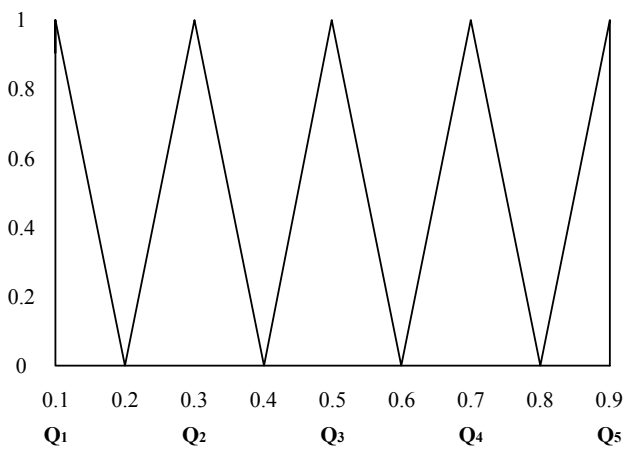

Fig. 2. Linguistic variables and triangular fuzzy numbers (Shi, Blomquist 2012) 


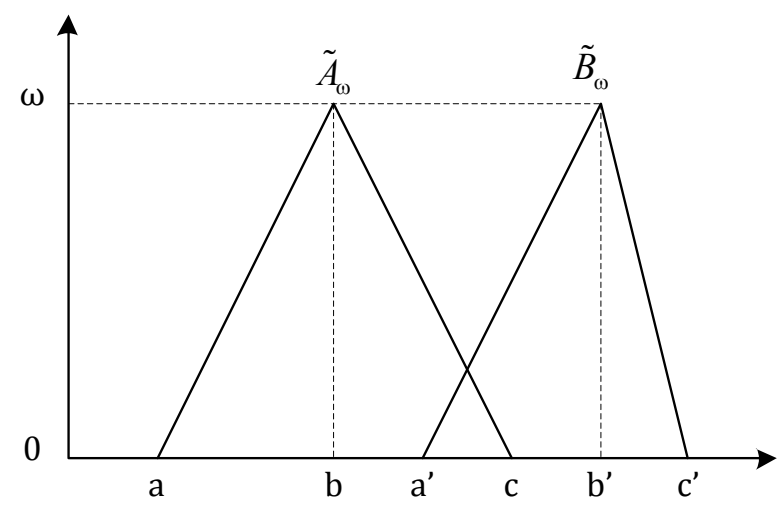

Fig. 3. Comparison of fuzzy set $\tilde{A}$ and $\tilde{B}$

If we compare two arbitrary fuzzy numbers $\tilde{A}_{\omega}$ and $\tilde{B}_{\omega^{\prime}}$ from Figure 3 at decision levels higher than $\alpha$ and $\alpha, \omega, \omega^{\prime} \in[0,1]$, we have:

$$
\tilde{A}_{\omega} \leq_{\alpha} \tilde{B}_{\omega^{\prime}} \leftrightarrow Q_{\alpha}\left(\tilde{A}_{\omega}\right) \leq Q_{\alpha}\left(\tilde{B}_{\omega^{\prime}}\right)
$$

Step 2: Calculate project cash flow according to $\alpha$ segments

Maravas and Pantouvakis (2012) proposed an algorithm for calculating project cash flow at every $\alpha$-level, which is adopted here.

The project cash flow can be calculated by summing up the cost distribution per unit of time for all activities throughout the entire project duration. The calculation is carried out by the following steps.

2A. Estimate fuzzy activity duration.

Figure 4 shows a sample fuzzy activity with $\widetilde{E S}=(a, b, c), \widetilde{E F}=(d, e, f)$. In the best case, the activity starts as early as possible and lasts the minimum duration. In the worst case, the activity begins as late as possible and lasts the maximum duration. Minimum duration intervals $\left(\min D_{\alpha}\right)$ indicate optimistic scenarios at all $\alpha$ levels and maximum duration intervals $\left(\max D_{\alpha}\right.$ ) represent pessimistic scenarios. Activity durations are calculated by:

$$
\begin{gathered}
\min D_{\alpha}=\left[\inf E S_{\alpha}, \inf E S_{\alpha}+\inf D_{\alpha}\right]= \\
{[\alpha(b-a)+a, \alpha(e-d)+d] ;} \\
\max D_{\alpha}=\left[\sup E S_{\alpha}, \sup E S_{\alpha}+\sup D_{\alpha}\right]= \\
{[\alpha(b-c)+c, \alpha(e-f)+f],}
\end{gathered}
$$

where: $\min D_{\alpha} / \max D_{\alpha}$ is the interval of the minimum/ maximum activity duration at each $\alpha$ cut, $D_{\alpha}$ is the $\alpha$ cut of the activity duration, $E S_{\alpha}$ is the $\alpha$ cut of the fuzzy early start, inf is infimum (least), sup is supremum (greatest).

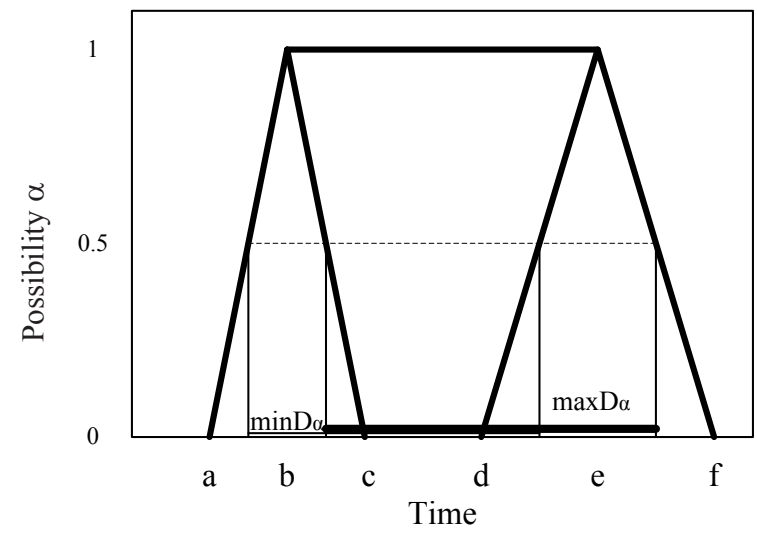

Fig. 4. Fuzzy activity start and completion date (Maravas, Pantouvakis 2012)

\section{B. Identify cost distribution.}

The cost distribution per unit of time can be identified by dividing the crisp activity cost by both the best and the worst scenarios of the activity duration. The cost distribution $(C D)$ per unit of time $t$ for activity $i$ at the $\alpha$ level for the best (min $C D_{i t_{\alpha}}$ ) and the worst scenario (max $C D_{i t_{\alpha}}$ ) are calculated as follows:

$$
\begin{aligned}
& \min C D_{i t_{\alpha}}=\frac{C_{i}}{\inf D_{i_{\alpha}}} ; \\
& \max C D_{i t_{\alpha}}=\frac{C_{i}}{\sup D_{i_{\alpha}}},
\end{aligned}
$$

where $C_{i}$ is the crisp cost of activity $i, D_{i_{\alpha}}$ is the $\alpha$ cut of the duration of activity $i$.

\section{C. Calculate project cash flow.}

For the whole project, the total cost $\left(C_{t}\right)$ at a specific time period $t$ at potential level $\alpha$ is the sum of the cost distribution per unit of time $t$ from each activity $(i=1$ to $n)$ :

$$
\begin{aligned}
& \min C_{t_{\alpha}}=\sum_{1}^{n} \min C D_{i t_{\alpha}} ; \\
& \max C_{t_{\alpha}}=\sum_{1}^{n} \max C D_{i t_{\alpha}} .
\end{aligned}
$$

The project cost curve (cash flow, CF) at level $\alpha$ is the cumulative plot of the cost per time period for the project duration $(t)$ :

$$
\begin{aligned}
& \min C F_{t_{\alpha}}=\sum_{0}^{T} \min C_{t_{\alpha}} ; \\
& \max C F_{t_{\alpha}}=\sum_{0}^{T} \max C_{t_{\alpha}} .
\end{aligned}
$$




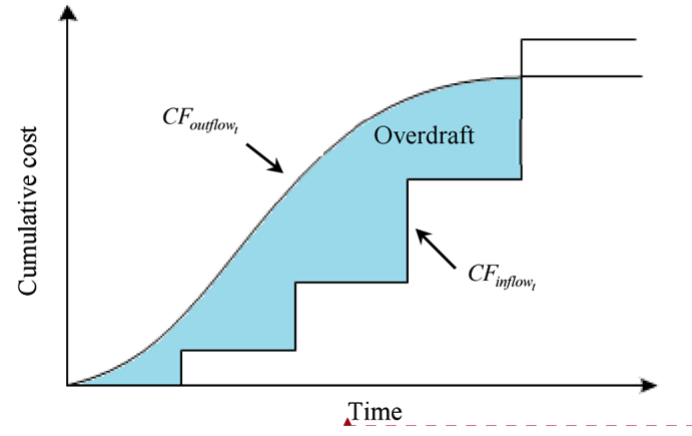

Fig. 5. Project overdraft requirement following:

The cash flow uncertainty $\left(C F U_{\alpha}\right)$ is defined by the

$$
C F U_{\alpha}=\min C F_{t_{\alpha}}-\max C F_{t_{\alpha}} .
$$

Step 3: Calculate project overdraft according to $\alpha$ segments

To calculate the required bank credit, the contractor needs to know the maximum overdraft amount during the life of the project. The effects of overdraft financing depend on the pattern of cash flows over time. Figure 5 illustrates the concept in Eqn (17). Project cash inflow and project cash outflow in the account at period $t$ are denoted by $C F_{\text {inflow.t }}$, and $C F_{\text {outflow.t }}$, respectively. The amount of overdraft, $O D$, at the end of period $t$ is the value of the difference between project cash inflow and project cash outflow and is defined as:

$$
O D_{t}=C F_{\text {inflow.t }}-C F_{\text {outflow.t }} .
$$

The difference between project cash inflow and project cash outflow in period $t$ can be either positive or negative, as can be the amount of overdraft. Most often, overdraft is negative during the early project phases and becomes positive in the later periods when the contractor has received payments exceeding expenses.

This study defines the project overdraft at level $\alpha$ is defined as:

$$
\min O D_{t_{\alpha}}=C F_{\text {inflow }_{t \alpha}}-\min C F_{t_{\alpha}}
$$

$$
\max O D_{t_{\alpha}}=C F_{\text {inflow }_{t \alpha}}-\max C F_{t_{\alpha}} .
$$

The contractor's overdraft uncertainty at level $\alpha$ $\left(O D U_{\alpha}\right)$ is defined as:

$$
\begin{gathered}
O D U_{\alpha}=\max O D_{t_{\alpha}}-\min O D_{t_{\alpha}}= \\
\min C F_{t_{\alpha}}-\max C F_{t_{\alpha}}=C F U_{\alpha} .
\end{gathered}
$$

Equation (20) illustrates that $C F U_{\alpha}$ has an effect on the uncertainty of overdraft requirements, meaning that the higher the cash flow uncertainty, the higher the uncertainty in overdraft requirements. The maximum $\mathrm{CFU}_{\alpha}$ value shows the highest uncertainty in overdraft requirements.

\section{A numeric example}

This section presents an application of the algorithm to illustrate the model and demonstrate its effectiveness for a project that includes eight activities. Table 2 shows the information dependencies. In the first column, the activities from A to $\mathrm{H}$ represent the project tasks, with the dependent relationships shown in the second column. In the third column, the duration of each activity is shown as a triangular fuzzy number. Both the direct and indirect costs such as overhead expenses are identified for each project activity and are shown in the fourth column.

This sample supposes that the project owner takes on the schedule risk by agreeing to pay the contractor after the completion of three milestones: complete activity $\mathrm{C}$, complete activity $\mathrm{F}$, and complete activity $\mathrm{H}$. The contractor would be paid $\$ 600, \$ 1,000$ and $\$ 380$ (a total of $\$ 1,980$ ) after the completion of milestones 1,2 , and 3 , respectively. Therefore, at the end of the project, there will be a profit of $\$ 180$.

Step 1: Manage schedule using the Dependency Structure Matrix

The triangular fuzzy number for the time factor based on the description of linguistic variables shown in Table 1 is calculated, along with the transformation rules from Figure 2. Figures 6 and 7 show the results of time factor for information exchange $B_{j i}$ (for all predecessor activities) and $C_{j i}$ (for all the successor activities), respectively.

Table 2. Sample activity network data

\begin{tabular}{cccccc}
\hline \multirow{2}{*}{ Activity } & Predecessors & Fuzzy duration (days) & \multicolumn{3}{c}{ Crisp cost (\$) } \\
\cline { 4 - 6 } & & $(17,18,19)$ & Direct costs & Overhead & Total costs \\
\hline A & Start & $(15,16,17)$ & 187 & 33 & 220 \\
B & Start & $(19,20,21)$ & 162 & 28 & 190 \\
C & A & $(14,15,16)$ & 153 & 27 & 180 \\
D & A & $(9,10,11)$ & 128 & 22 & 150 \\
E & A,B & $(29,30,31)$ & 35 & 15 & 100 \\
F & C,D & $(14,15,16)$ & 102 & 54 & 360 \\
G & E & $(42,43,44)$ & 408 & 72 & 120 \\
H & F,G & & & 780 \\
\hline
\end{tabular}




\begin{tabular}{|c|c|c|c|c|c|c|c|c|c|}
\hline$\tilde{B}_{j i}$ & STA & A & B & $\mathrm{C}$ & $\mathrm{D}$ & $\mathrm{E}$ & $\mathrm{F}$ & $\mathrm{G}$ & $\mathrm{H}$ \\
\hline STA & & & & & & & & & \\
\hline A & $1,1,1$ & & & & & & & & \\
\hline B & $1,1,1$ & & & & & & & & \\
\hline $\mathrm{C}$ & & $\begin{array}{l}0.8 \\
0.9 \\
0.9\end{array}$ & & & & & & & \\
\hline D & & $\begin{array}{l}0.6 \\
0.7 \\
0.8\end{array}$ & & & & & & & \\
\hline $\mathrm{E}$ & & $\begin{array}{l}0.8 \\
0.9 \\
0.9\end{array}$ & $\begin{array}{l}0.8 \\
0.9 \\
0.9\end{array}$ & & & & & & \\
\hline $\mathrm{F}$ & & & & $\begin{array}{l}0.8 \\
0.9 \\
0.9\end{array}$ & $\begin{array}{l}0.6 \\
0.7 \\
0.8\end{array}$ & & & & \\
\hline $\mathrm{G}$ & & & & & & $\begin{array}{l}0.8 \\
0.9 \\
0.9\end{array}$ & & & \\
\hline $\mathrm{H}$ & & & & & & & $\begin{array}{l}0.8 \\
0.9 \\
0.9\end{array}$ & $\begin{array}{l}0.8 \\
0.9 \\
0.9\end{array}$ & \\
\hline
\end{tabular}

Fig. 6. Matrix $B_{j i}-$ Time factor relationships for the predecessor activities

\begin{tabular}{|c|c|c|c|c|c|c|c|c|c|}
\hline$\tilde{C}_{j i}$ & STA & A & B & $\mathrm{C}$ & D & E & $\mathrm{F}$ & $\mathrm{G}$ & $\mathrm{H}$ \\
\hline \multicolumn{10}{|c|}{ STA } \\
\hline A & $0,0,0$ & & & & & & & & \\
\hline B & $0,0,0$ & & & & & & & & \\
\hline $\mathrm{C}$ & & $\begin{array}{l}0.1 \\
0.1 \\
0.2\end{array}$ & & & & & & & \\
\hline D & & $\begin{array}{l}0.1 \\
0.1 \\
0.2\end{array}$ & & & & & & & \\
\hline $\mathrm{E}$ & & $\begin{array}{l}0.2 \\
0.3 \\
0.4\end{array}$ & $\begin{array}{l}0.1 \\
0.1 \\
0.2\end{array}$ & & & & & & \\
\hline $\mathrm{F}$ & & & & $\begin{array}{l}0.2 \\
0.3 \\
0.4\end{array}$ & $\begin{array}{l}0.1 \\
0.1 \\
0.2\end{array}$ & & & & \\
\hline G & & & & & & $\begin{array}{l}0.1 \\
0.1 \\
0.2\end{array}$ & & & \\
\hline $\mathrm{H}$ & & & & & & & $\begin{array}{l}0.1 \\
0.1 \\
0.2\end{array}$ & $\begin{array}{l}0.1 \\
0.1 \\
0.2\end{array}$ & \\
\hline
\end{tabular}

Fig. 7. Matrix $C_{j i}$ - Time factor relationships for the successor activities
Eqns (2) and (3) are applied to calculate $(\widetilde{E S})_{j}$ and $(\widetilde{E F})_{j}$. In order to demonstrate how the calculation of fuzzy time can be carried out, an example for activity A and $\mathrm{C}$ with task overlaps is presented:

$$
\begin{gathered}
(\widetilde{E S})_{A}=(0,0,0) \quad \text { (no predecessor); } \\
(\widetilde{E F})_{A}=\left(\widetilde{E S)_{A}} \oplus \tilde{C}_{11} \quad(j=1, n=8)\right. \\
=(0,0,0) \oplus(17,18,19)=(17,18,19) ; \\
(\widetilde{E S})_{C}=\max \left[(\widetilde{E S})_{A} \oplus\left(\tilde{B}_{31} \otimes \tilde{B}_{11}\right) \oplus\left(\tilde{C}_{31} \otimes \tilde{C}_{33}\right)\right] \\
(i=1, j=3, n=8) \\
=\max [(0,0,0) \oplus((0.8,0.9,0.9) \otimes(17,18,19)) \odot \\
((0.1,0.1,0.2) \otimes(19,20,21))]=(9.4,14.2,15.2) ; \\
(\widetilde{E F})_{C}=\left(\widetilde{E S)_{C}} \oplus \tilde{C}_{33}(j=3, n=8)\right. \\
=(9.4,14.2,15.2) \oplus(19,20,21)=(28.4,34.2,36.2) .
\end{gathered}
$$

Table 3. Time variable calculations without overlaps

\begin{tabular}{c|c|c}
\hline Activity Name & $\widetilde{\boldsymbol{E S}}$ & $\widetilde{\boldsymbol{E F}}$ \\
\hline STA & $(0,0,0)$ & $(0,0,0)$ \\
A & $(0,0,0)$ & $(17,18,19)$ \\
B & $(0,0,0)$ & $(15,16,17)$ \\
C & $(17,18,19)$ & $(36,38,40)$ \\
D & $(17,18,19)$ & $(31,33,35)$ \\
E & $(17,18,19)$ & $(26,28,30)$ \\
F & $(36,38,40)$ & $(65,68,71)$ \\
G & $(26,28,30)$ & $(40,43,46)$ \\
H & $(65,68,71)$ & $(107,111,115)$ \\
\hline
\end{tabular}

Table 4. Time variable calculations with overlaps

\begin{tabular}{c|c|c}
\hline Activity Name & $\widetilde{\boldsymbol{E S}}$ & $\widetilde{\boldsymbol{E F}}$ \\
\hline STA & $(0,0,0)$ & $(0,0,0)$ \\
A & $(0,0,0)$ & $(17,18,19)$ \\
B & $(0,0,0)$ & $(15,16,17)$ \\
C & $(9.4,14.2,15.2)$ & $(28.4,34.2,36.2)$ \\
D & $(7,11.1,13.8)$ & $(21,26.1,29.8)$ \\
E & $(9.2,13.2,15.3)$ & $(18.2,23.2,26.3)$ \\
F & $(12.2,23.2,28.3)$ & $(41.2,53.2,59.3)$ \\
G & $(13.2,20.7,23.8)$ & $(27.2,35.7,39.8)$ \\
H & $(26.6,45.9,52)$ & $(68.6,88.9,96)$ \\
\hline
\end{tabular}


Repeat the above two equations successively for all the $n$ activities. Tables 3 and 4 list the results of the fuzzy early start $\widetilde{E S}$ and fuzzy early finish $\widetilde{E F}$ calculations according to Eqns (2) and (3).

Gantt charts graphically show project progress, as project management is easier when the project is viewed as small manageable items with clearly illustrated dependencies, parallel processes, the overall time, and progress. This example introduces a Fuzzy Gantt chart to illustrate the project schedule, which differs from a traditional Gantt chart in that activity durations are defined by fuzzy start and finish dates calculated from the forward pass using DSM. Figures 8 and 9 illustrate 2-dimensional fuzzy Gantt schedules without and with overlap, respectively. The x-axis shows project time, and the y-axis shows both activity names and membership functions of the fuzzy start and finish dates. The charts also illustrate the overlaps. The start date for activity $\mathrm{C}$ depends on the finish date of activity A and the information exchange between these two activities. The project completion date is the end date for activity $\mathrm{H}$, which has a large amount of uncertainty between its start date and finish dates, as this activity is affected by all predecessors.

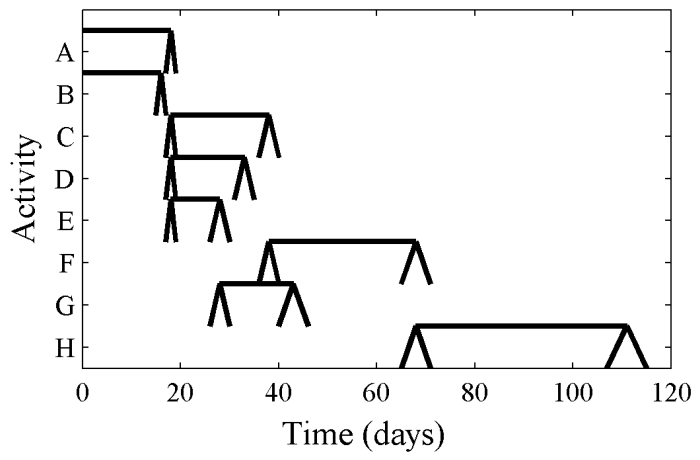

Fig. 8. Fuzzy Gantt Chart-2D without overlap

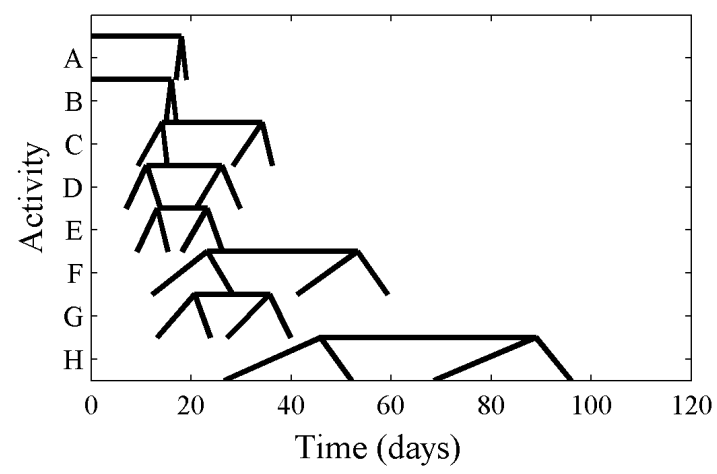

Fig. 9. Fuzzy Gantt Chart-2D with overlap

Figures 10 and 11 illustrate the role of the $\alpha$-factor (possibility) in 3-dimensional Gantt charts without and with overlapping activities, respectively.

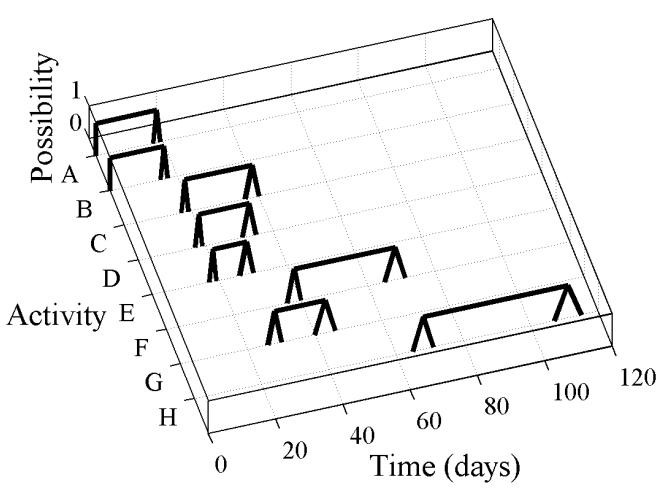

Fig. 10. Fuzzy Gantt Chart-3D without overlap

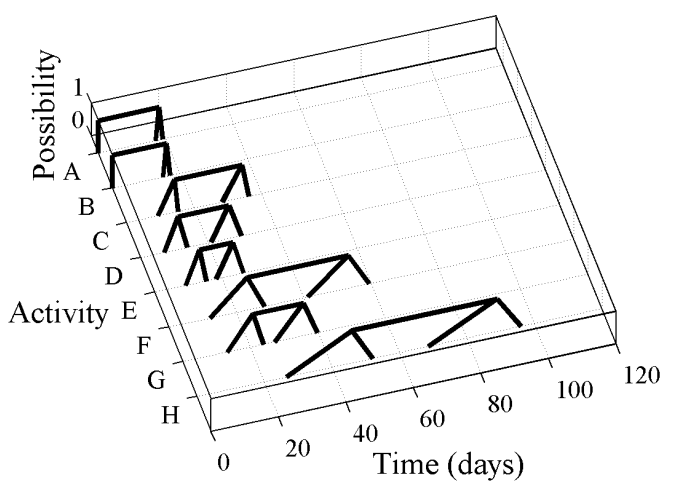

Fig. 11. Fuzzy Gantt Chart-3D with overlap

Step 2: Calculate distribution cost according to $\alpha$ segments

Figures 12 and 13 illustrate project cash flows from several $\alpha$ levels without and with overlap, respectively. The $\alpha$ level project cash flow is calculated according to Eqns (14) and (15). Note that the project cash flow at level $\alpha$ is the cumulative plot of the cost per time period for the project duration. Therefore, when $\alpha$ level equals 1, the cash flow (black line) is a unique S-Curve because there is no uncertainty in the task durations, and thus no uncertainty in the cost.

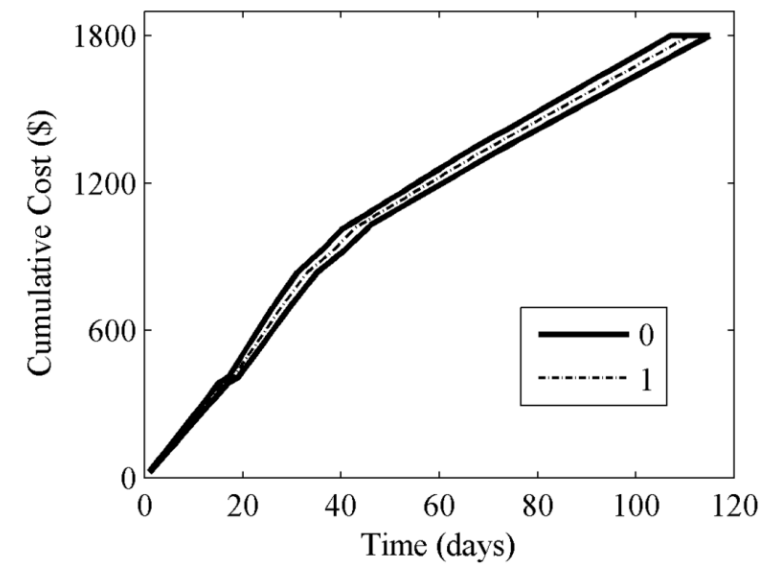

Fig. 12. Fuzzy cash flow without task overlaps 


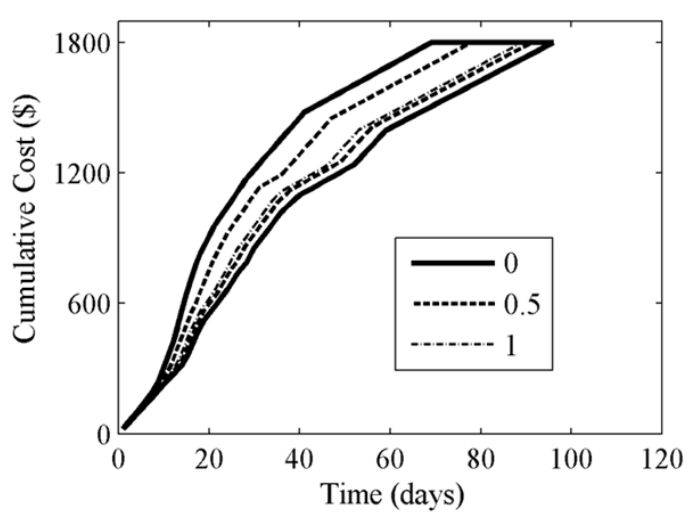

Fig. 13. Fuzzy cash flow with task overlaps

With an $\alpha$ level equal to 0.5 (dotted line), optimistic cash flows appear on the left, and pessimistic estimates on the right, illustrating cash flow uncertainty. However, an $\alpha$ level equal to 0 yields a wider spread in the optimistic and pessimistic lines, indicating a higher degree of uncertainty. The project will finish in 68.6 days in the best case ( $\alpha=0$, optimistic line) and in 96 days in the worst case ( $\alpha=0$, pessimistic line).
This research also implements S-Surfaces (Maravas, Pantouvakis 2012), which differ from traditional S-Curves in that they give project managers an overall picture of project cash flows at any possibility level. Figures 14 and 15 plot the project S-Surfaces without and with overlap, respectively. These are plotted by connecting the S-Curves of different possibility levels at specific time intervals. The advantage of the S-Surfaces is that time and the uncertainty level both impact project cash flow.

As the $\alpha$ level moves from 0 to 1 , the points of each surface will move closer together. At $\alpha=1$, the best and worst surfaces intersect to form a standard deterministic S-Curve.

The S-surface is analyzed using surface cross sections at specific times to compare the degree of uncertainty in project cash flow before and after the overlapping activity. Figure 16 shows a cross section of the S-surface without and with overlap at days 5,30 , and 75 . When the level $\alpha$ moves from 0 to 1 , the cost variance of the best and worst case will move from its highest value to zero. In particular, the cost variance of the best and worst case with and without overlap at possibility level 0 on days 5 , 30 , and 75 are $(\$ 14.25, \$ 14.25),(\$ 360.62, \$ 99.12)$, and (\$228.86, \$70.39), respectively.

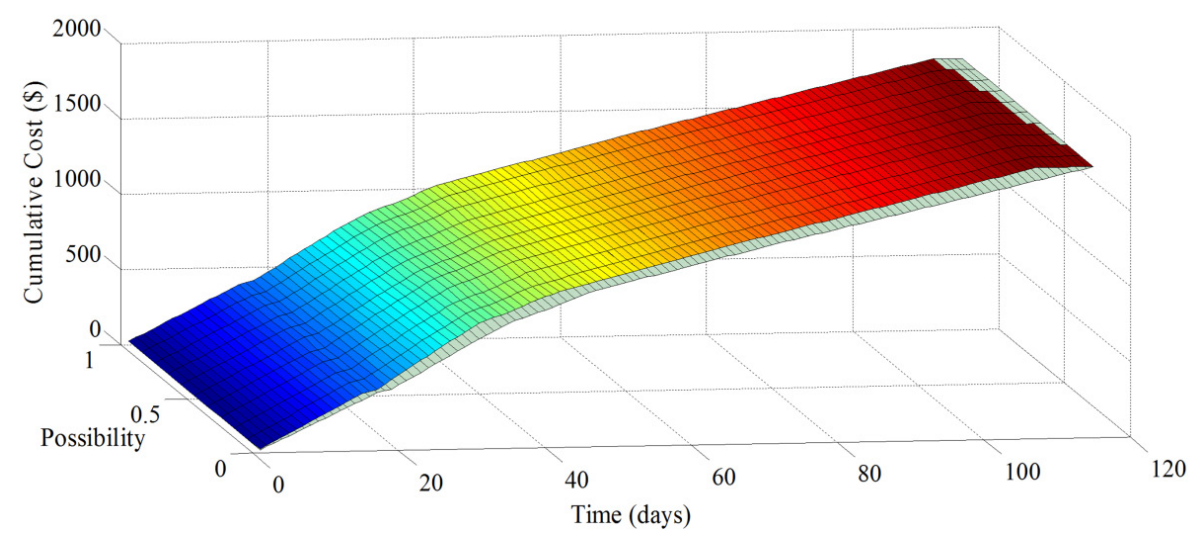

Fig. 14. Project S-Surface without task overlaps

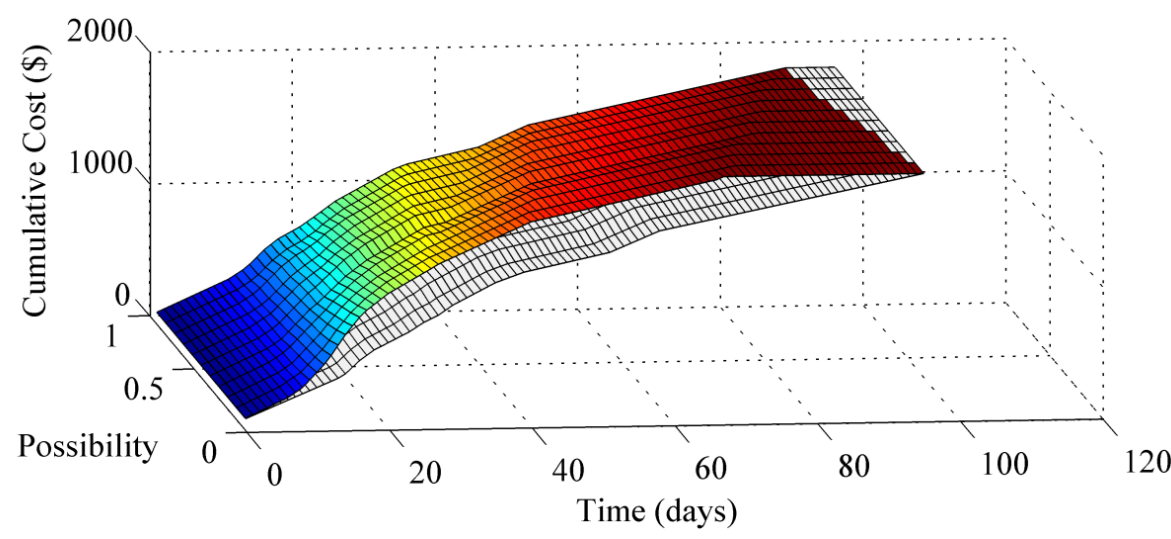

Fig. 15. Project S-Surface with task overlaps 

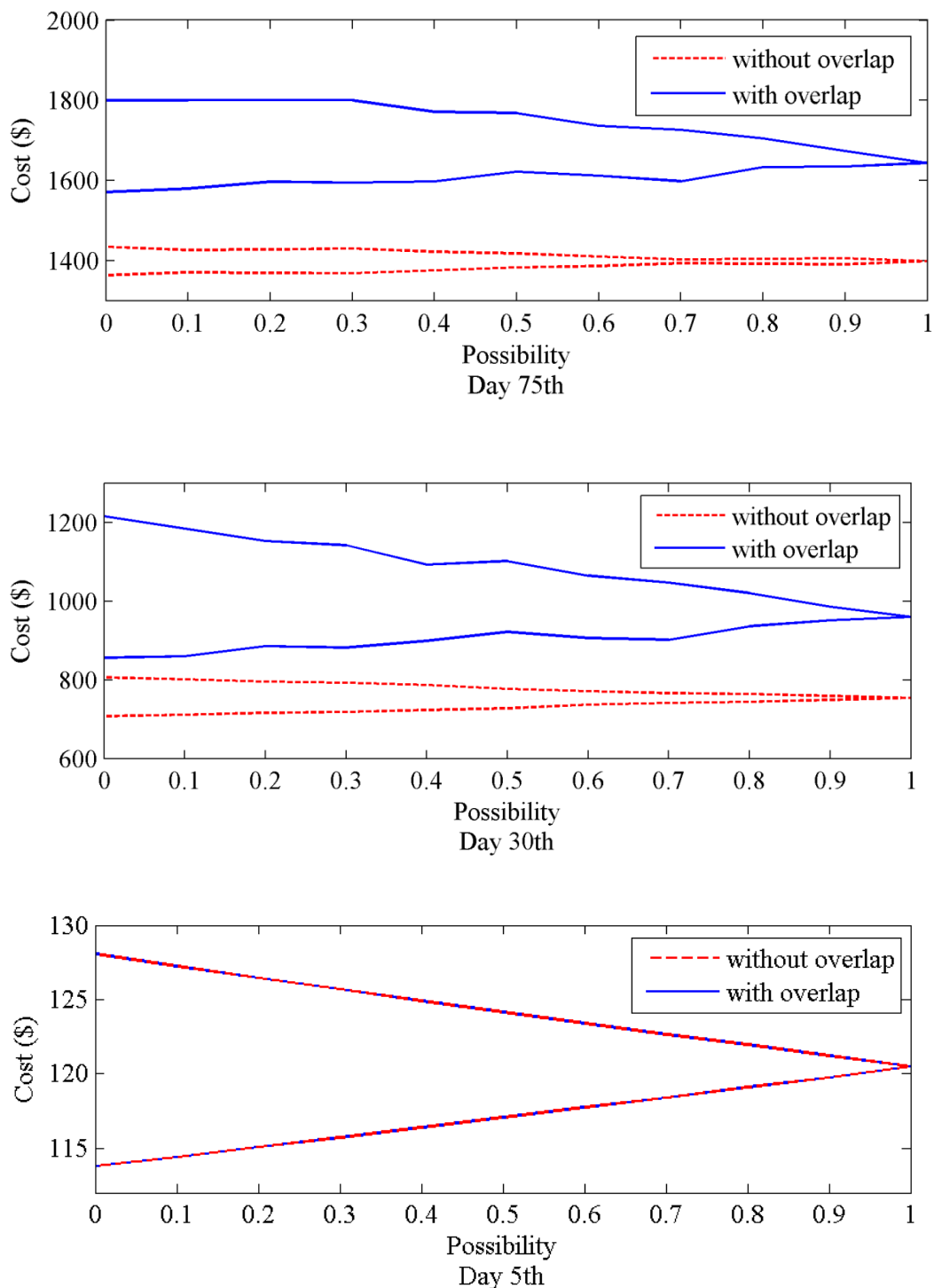

Fig. 16. S-surface cross-section at three time periods without and with task overlaps

On day 5, the S-surface cross sections with and without overlapping tasks are concurrent, meaning that there is no difference in the cost variance, so the cross section for both task scenarios changes only on day 7 , on when activity D begins to overlap with activity A. Note that the cross section with overlap will be always higher than the cross section without overlap because more tasks are excluded, though it requires more cash expenditures. Projects with overlap will end sooner, but with more uncertainty and risk in cash flows. On day 30 , the costs at possibility level 1 without and with overlap are $\$ 754$ and $\$ 960$, respectively. As with day 75 , these values are $\$ 1,398$ and $\$ 1,644$, respectively. In the best case at day 75 , with overlap, the cost has leveled between possibility levels 0 and 0.3 . Thus, in this case, the project with overlapping tasks will end after 75 days at a possibility level of 0.3 .
Step 3: Calculate project overdraft according to $\alpha$-cut

Besides the inherent uncertainty in the project cash flow, the information between activities affects the entire project overdraft. Thus, a project plan with overlapping tasks leads to different overdraft requirements. Figure 17 shows the plot of the overdraft requirements against project duration, and indicates the financial requirements of the two plans developed for the project. It is obvious that as the project duration decreases, the rate of cash expenditure increases, and the maximum overdraft similarly increases. These graphs show that project durations of about 96 and 115 days would require a maximum overdraft of $\$ 1136.6$ and $\$ 988.5$, respectively. Clearly, it may be necessary to schedule the project according to the available overdraft limits rather than to adopt the all-normal solution.

A contractor will naturally want to reduce their financing amount to zero and avoid financing the project 

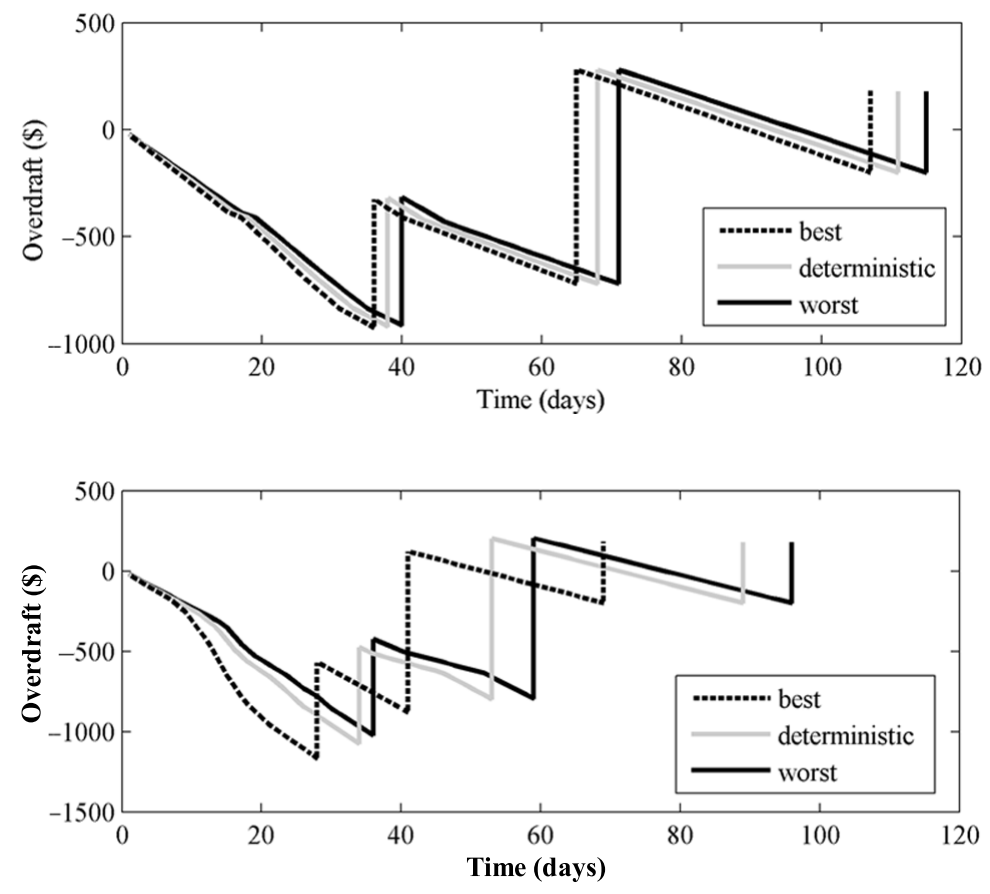

Fig. 17. Maximum overdraft at three possibility levels without task overlaps (top) and with task overlaps (bottom)
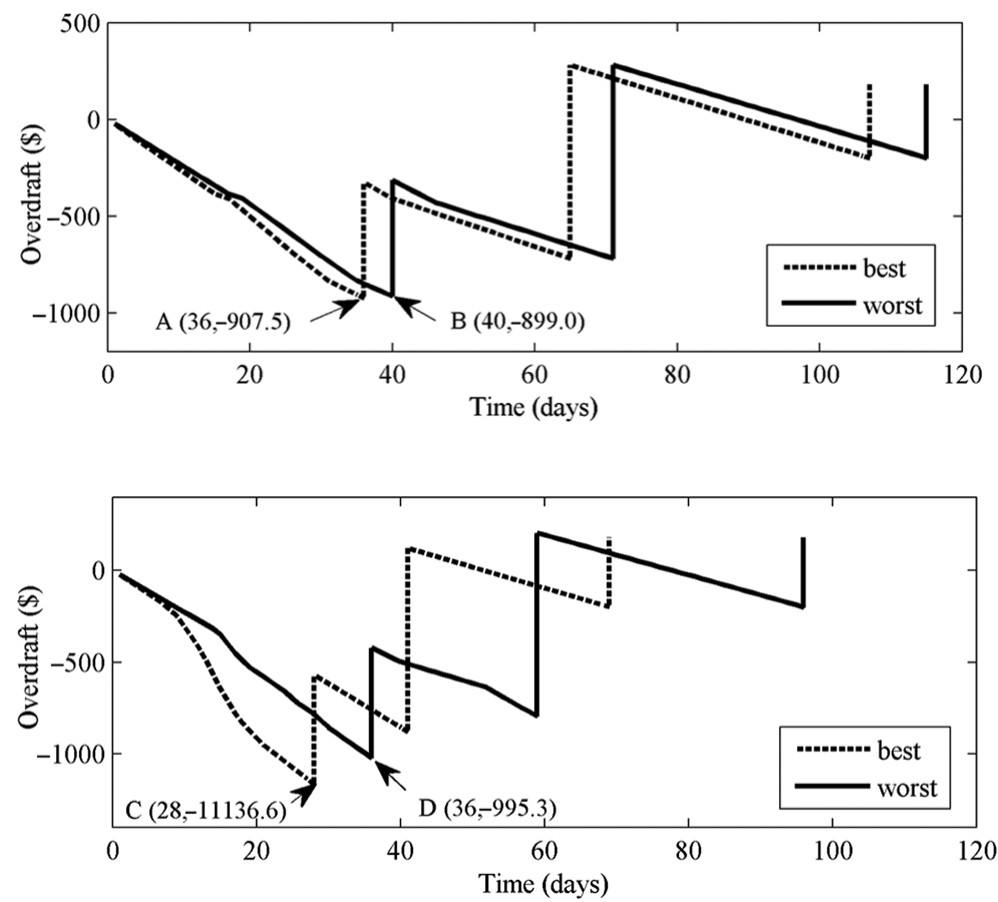

Fig. 18. Project overdraft at possibility level 0 without task overlaps (top) and with task overlaps (bottom)

overdraft. Some publicly-funded projects allow the contractor to charge a mobilization item at the beginning of the project to reduce the amount of overdraft. Realistically, a project's cash flow is optimized from a contractor's perspective when it ties up as little of the contractor's money as possible. A project has an optimum cash flow when the cash inflow curve is as close as possible to the cash outflow curve. Therefore, strategies that minimize the distance between these two curves are required. Overdraft is reduced if the payment curve is shifted as much as possible to the left, implying that money is received as soon as possible or as an advance (mobilization) payment. Moving the outflow curve as much as possible to the right also reduces the distance between the 
two curves, reducing the maximum cash overdraft. This is achieved when payments are delayed as much as possible. Figure 17 illustrates the maximum overdraft at three possibility levels for projects without and with overlap.

Figure 18 plots these project overdrafts together at possibility level 0 to indicate a boundary of the maximum overdraft and a boundary of the completion time for both cases. Specifically, a project without overlap will have a maximum overdraft in the range of $\$ 899$ to $\$ 907.5$ and a completion time in the range of 107 to 115 days. Similarly, a project with overlap will have a maximum overdraft in the range of $\$ 995.3$ to $\$ 1136.6$ and a completion time in the range of 68.6 to 96 days. Relying on these results, the project manager can decide whether to bid for the project, and determine the project duration and optimum start times to avoid a financial crisis within the company.

Note, however, that this analysis does not consider interest paid on the overdraft. These interest charges will further reduce project's margins so that the final profit on this project will be less than $\$ 180$.

\section{Conclusions}

This study aimed to estimate the uncertainty of cash flows and overdraft requirements that are important for a project manager creating a plan for a project that includes activities with fuzzy duration and overlaps. Overlapping activities are sometimes unavoidable in order to reduce the project time duration. To reduce the effects of overlapping on cash flows and overdrafts, the project manager has to identify and qualify the risk caused by overlapping at every $\alpha$ risk level.

The mathematical algorithm described in this research can help a contractor fully estimate project cash flows and overdrafts in activity networks with overlapping and fuzzy duration at every risk level. Simultaneously, this helps contractors reduce the overdraft required to support overlapping activities, and provides useful information for negotiating the payment plan. Moreover, the algorithms' output provides information to financial managers who are responsible for securing sufficient project capital reserves.

Different $\alpha$ segments can be considered separate risk levels. A risk analysis is conducted for cash flow and overdraft with the appropriate $\alpha$ segments. When these move from 1 to 0 , the risk levels vary similarly from none, to low, and to high. At the same time, an analysis at several possibility levels is necessary to attain a better picture of the effects of risk on project cash flows and overdraft requirements.

The results suggested that the inclusion of overlap tends to incur higher amount of overdraft while shortening the project completion time and leads to greater cash flow uncertainty. However, project managers must determine whether the project should be bid beforehand by conducting the trade-off analysis between the cost of overdraft and the profit of the project.
Real-world project management is often hampered by the uncertain nature regarding activity durations, costs, and cash flows. Although the proposed algorithm involves a variety of mathematical theories, its application in practical cash flow analyses of project management is not unattainable. Maravas and Pantouvakis (2012) have proved that the fuzzy cash flow analysis can be applied in a real-world highway construction project. As for fuzzy DSM, Shi and Bloquist (2012) as well this study provide practical capability to evaluate project proposals during the feasibility analysis phase.

\section{References}

Browning, T. R. 1998. Use of dependency structure matrices for product development cycle time reduction, in Proceedings of the Fifth ISPE International Conference on Concurrent Engineering: Research and Applications, 15-17 July 1998, Tokyo, Japan, 89-96.

Browning, T. R. 2001. Applying the design structure matrix to system decomposition and integration problems: a review and new directions, IEEE Transactions on Engineering Management 48(3): 292-306.

https://doi.org/10.1109/17.946528

Chen, C. H.; Ling, S. F.; Chen, W. 2003. Project scheduling for collaborative product development using DSM, International Journal of Project Management 21(4): 291-299. https://doi.org/10.1016/S0263-7863(02)00023-6

Cui, Q.; Hastak, M.; Halpin, D. 2010. Systems analysis of project cash flow management strategies, Construction Management and Economics 28(4): 361-376. https://doi.org/10.1080/01446191003702484

Dubois, A.; Gadde, L. E. 2002. The construction industry as a loosely coupled system: implications for productivity and innovation, Construction Management and Economics 20(7): 621-631.

https://doi.org/10.1080/01446190210163543

Easa, S. M. 1992. Optimum cash-flow scheduling of construction projects, Civil Engineering Systems 9(1): 69-85. https://doi.org/10.1080/02630259208970640

Halpin, D. W. 2010. Construction management. John Wiley \& Sons.

Halpin, D. W.; Senior, B. A. 2011. Financial management and accounting fundamentals for construction. John Wiley \& Sons.

Hendrickson, C.; Au, T. 1989. Project management for construction: Fundamental concepts for owners, engineers, architects, and builders. Prentice-Hall.

Hwee, N. G.; Tiong, R. L. 2002. Model on cash flow forecasting and risk analysis for contracting firms, International Journal of Project Management 20(5): 351-363. https://doi.org/10.1016/S0263-7863(01)00037-0

Jeang, A. 2015. Project management for uncertainty with multiple objectives optimisation of time, cost and reliability, International Journal of Production Research 53(5): 1503 1526. https://doi.org/10.1080/00207543.2014.952792

Kaka, A. P.; Price, A. D. F. 1991. Net cashflow models: Are they reliable?, Construction Management and Economics 9(3): 291-308. https://doi.org/10.1080/01446199100000023

Kazaz, A.; Ulubeyli, S.; Tuncbilekli, N. A. 2012. Causes of delays in construction projects in Turkey, Journal of Civil Engineering and Management 18(3): 426-435. https://doi.org/10.3846/13923730.2012.698913

Kerzner, H. R. 2013. Project management: a systems approach to planning, scheduling, and controlling. John Wiley \& Sons. 
Khodakarami, V.; Fenton, N.; Neil, M. 2007. Project scheduling: Improved approach to incorporate uncertainty using Bayesian Networks, Project Management Journal 38(2): 39-49.

Maheswari, J. U.; Varghese, K. 2005. Project scheduling using dependency structure matrix, International Journal of Project Management 23(3): 223-230. https://doi.org/10.1016/j.ijproman.2004.10.001

Maravas, A.; Pantouvakis, J. P. 2012. Project cash flow analysis in the presence of uncertainty in activity duration and cost, International Journal of Project Management 30(3): 374-384. https://doi.org/10.1016/j.ijproman.2011.08.005

Shankar, N. R.; Raju, M. M. K.; Srikanth, G.; Bindu, P. H. 2011. Time, cost and quality trade-off analysis in construction of projects, Contemporary Engineering Sciences 4(6): 289-299.
Shi, Q.; Blomquist, T. 2012. A new approach for project scheduling using fuzzy dependency structure matrix, International Journal of Project Management 30(4): 503-510. https://doi.org/10.1016/j.ijproman.2011.11.003

Shureshjani, R. A.; Darehmiraki, M. 2013. A new parametric method for ranking fuzzy numbers. Indagationes Mathematicae 24(3): 518-529. https://doi.org/10.1016/j.indag.2013.02.002

Skitmore, M. 1992. Parameter prediction for cash flow forecasting models, Construction Management and Economics 10(5): 397-413. https://doi.org/10.1080/01446199200000038

Snyder, C. S. 2013. A user's manual to the PMBOK guide. John Wiley \& Sons.

Steward, D. V. 1981. The design structure system: a method for managing the design of complex systems, IEEE Transactions on Engineering Management 28: 71-74. https://doi.org/10.1109/TEM.1981.6448589

Min-Chun YU. He is an Associate Professor in the Department of Business Administration at the National Kaohsiung University of Applied Sciences in Taiwan. He has a BS in Management Science from National Chiao-Tung University of Taiwan (1985), an MBA in Marketing from University of Memphis (1990) and a PhD in Industrial Engineering and Management from Oklahoma State University (1997). His research interests include project management, supply chain management and decision science. He has published research papers in Journals such as European Journal of Operations Research, International Journal of Production Research, Computers in Human Behavior, International Journal of System Science, International Journal of Logistics Research and Application, and International Journal of Advanced Manufacturing Technology.

Van-Loi DANG. He is a SQE leader in the Quality Assurance Department of Foxconn Technology Group. He has a BS in Mechatronics from Hanoi University of Science and Technology of Vietnam (2011), and an MS in Industrial Engineering and Management from National Kaohsiung University of Applied Sciences of Taiwan (2015). His research interests include project management, lean manufacturing, technology management, and social marketing.

Hui-Chung YEH. He is an Associate Professor in the Department of Business Administration at the National Kaohsiung University of Applied Sciences in Taiwan. He has a master degree in Industrial Management from National Cheng Kung University (1990) and a PhD in Business Administration from National Sun Yat-Sen University (2000). His research interests include project management, credit assessment, and decision science. He has published research papers in Journals such as Journal of the Operational Research Society and IMA Journal of Mathematics Applied in Business \& Industry. 